\title{
Increased Dopamine Efflux from Striatal Slices During Development and After Nigrostriatal Bundle Damage
}

\author{
Michal K. Stachowiak, Richard W. Keller, Jr., Edward M. Stricker, and Michael J. Zigmond \\ Departments of Behavioral Neuroscience, Biological Sciences and Psychiatry and the Center for Neuroscience, University \\ of Pittsburgh, Pittsburgh, Pennsylvania 15260
}

Dopaminergic control over striatal targets appears to be retained in rats sustaining lesions of the nigrostriatal dopamine (DA) system as long as $5-10 \%$ of that projection remains. Similarly, during postnatal development, dopaminergic control over striatal neurons matures well before the innervation of striatum by the nigrostriatal bundle is attained. These observations suggest that enhanced efficacy of dopaminergic transmission may compensate for hypoinnervation of striatum after lesions or during development. To examine this hypothesis, striatal slices were superfused with Krebs bicarbonate buffer and effluent was collected and analyzed for endogenous DA. Electrical field stimulation $(2 \mathrm{~Hz})$ continuously delivered to slices prepared from intact adult rats increased DA efflux to 3-5 times the prestimulation rate within $10 \mathrm{~min}$. Efflux then fell to approximately twice the basal rate over the next 20 min. DA efflux was also examined using slices prepared from adult animals given 6-hydroxydopamine 2-3 weeks earlier, and from $7-10-d-o l d$ rat pups. In each group, striatal DA levels were $10-40 \%$ of adult control values. Nevertheless, stimulated DA efflux from these slices attained the same rate as that observed with intact, adult slices. Thus, fractional DA efflux from these slices was several times higher than the control rate by the end of the stimulation period. This increased DA efflux appeared to be a consequence of both increased release and decreased reuptake of DA, as the fractional DA efflux from control striatal slices could not be increased to the rate seen in hypoinnervated slices using nomifensine $(10 \mu \mathrm{M})$, an inhibitor of DA efflux. Moreover, increased DA biosynthesis was indicated by the maintenance of DA stores in the hypoinnervated slices during stimulation. Thus, increased DA release, decreased reuptake, and increased synthesis may serve to compensate for hypoinnervation after injury or during development.

The dopamine (DA)-containing neurons of the nigrostriatal bundle have significant influences on striatal function, as measured at both the cellular and behavioral levels (Ungerstedt, 1971; Zigmond and Stricker, 1973; Marshall et al., 1974; Agid

\footnotetext{
Received June 24, 1986; revised Jan. 2, 1987; accepted Jan. 8, 1987.

We thank Dr. John P. Bruno for providing neonatal rats and for fruitful discussions, the Carnegie-Mellon University Graphics Department for preparing the figures, and Kendall Stanley and Terri Komar for typing the manuscript. This research was supported in part by USPHS Grants MH-00058, MH-00338, MH30915, and NS-19608 and by a grant from the American Parkinson Disease Association. A preliminary report was presented at the Fourteenth Annual Meeting of the Society for Neuroscience (Stachowiak et al., 1984).

Correspondence should be addressed to Dr. Michael J. Zigmond, Department of Behavorial Neuroscience, 570 Crawford Hall, University of Pittsburgh, Pittsburgh, PA 15260.

Copyright (C) 1987 Society for Neuroscience $0270-6474 / 87 / 061648-07 \$ 02.00 / 0$
}

et al., 1975; Rommelspacher and Kuhar, 1975; Schultz and Ungersted 1978; and others). However, these influences appear to be relatively independent of the density of innervation. Thus, dopaminergic influences mature well before the nigrostriatal bundle is fully developed (Lal and Sourkes, 1973; Baez et al., 1976; Coyle and Campochiaro, 1976). Moreover, in adult animals it is possible to destroy up to $90 \%$ of the bundle without permanent disruption of either cellular function or behavior (Zigmond and Stricker, 1973; Creese and Snyder, 1979; MacKenzie et al., 1985; Orr et al., 1986). These latter results cannot be attributed to alterations in the number of postsynaptic receptors, since neonatal rats do not have more DA receptors than adults do (Pardo et al., 1977), and, after DA-depleting lesions in adult animals, postsynaptic supersensitivity occurs only after the loss of at least $90 \%$ of striatal DA content (Creese and Snyder, 1979; Zigmond and Stricker, 1980). Instead, there is considerable evidence that, after brain damage in adult rats, the synthesis and turnover of DA within the existing dopaminergic terminals are increased relative to the rates in intact control animals (Agid et al., 1973; Hefti et al., 1980; Zigmond et al., 1984). The increased turnover that occurs after DA depletions of $50-60 \%$ or more may reflect an increase in the capacity of these terminals to release DA and thereby compensate for the loss.

The use of brain slices provides a useful experimental approach with which to examine this hypothesis. Such a preparation retains several properties of intact brain tissue, including the capacity for calcium-dependent transmitter release (Raiteri et al., 1984). Slices from striatum contain axon terminals of the dopaminergic nigrostriatal bundle, as well as of other neuronal and non-neuronal elements. Although the dopaminergic terminals are devoid of the spontaneous action potentials normally generated in cell bodies located in substantia nigra, once depolarized they release DA in a calcium- and frequency-dependent manner and thereby affect other elements within the slice (Farnebo and Hamberger, 1971; Starke et al., 1978; Cubeddu and Hoffman, 1983). In this report we have used striatal tissue slices to study depolarization-induced DA efflux in 2 groups of animals: neonatal rats with incomplete dopaminergic innervation of striatum, and adult rats after partial injury of nigrostriatal bundle caused by pretreatment with the neurotoxin 6-hydroxydopamine (6-HDA). Our findings suggest that, in both groups, there is an elevated capacity for DA release as well as a decreased rate of DA reuptake, leading to an increase in transmitter availability in extracellular fluid.

\section{Materials and Methods}

Materials. Dopamine $\mathrm{HCl}$, Sephadex G-25, 6-HDA hydrobromide, pargyline and BSA (fraction V) were obtained from Sigma Chemical 
Co., St. Louis, MO. 6-Methyl-5, 6, 7, 8-tetrahydropterin $\mathrm{HCl}\left(6 \mathrm{MPH}_{4}\right)$ was obtained from Calbiochem-Behring, La Jolla, CA, and ${ }^{3} \mathrm{H}-$ dopamine-[ethyl-1-3H(N)] was obtained from New England Nuclear, Boston, MA. Desipramine was the gift of Merrell National Labs, Cincinnati, $\mathrm{OH}$, and nomifensine maleate the gift of Hoechst-Roussel Pharmaceuticals, Somerville, NJ. All remaining reagents were purchased from Fisher Scientific, Pittsburgh, PA, and were of the highest obtainable purity.

Animals. Male Sprague-Dawley rats were used in all experiments. Adult rats weighing 200-250 gm were obtained from Zivic-Miller Laboratories (Allison Park, PA), whereas neonatal rats derived from parents of the same strain were raised in litters of 8-10 in our colony. Adult animals were allowed free access to Purina Rodent Laboratory Chow (Ralston Purina, St. Louis, MO) and tap water, and were housed in a temperature-controlled room $\left(23-25^{\circ} \mathrm{C}\right)$ in which illumination was provided from 8 A.M. to 8 P.M.

Adult rats were anesthetized with ether, and then 6-HDA (150-250 $\mu \mathrm{g}$ free base) was administered into the lateral cerebroventricles (Noble et al., 1967). Thirty minutes earlier, the animals had been treated with desipramine $(25 \mathrm{mg} / \mathrm{kg}$, i.p.) to block the effects of the neurotoxin on noradrenergic terminals, and with pargyline $(40 \mathrm{mg} / \mathrm{kg}$, i.p.) to inhibit monoamine oxidase and thereby enhance the neurotoxicity of 6-HDA (Breese and Traylor, 1970). Control animals either received desipramine, pargyline, and the 6-HDA vehicle $(20 \mu \mathrm{l}$ of a $0.9 \% \mathrm{NaCl}$ solution containing $0.1 \%$ ascorbic acid) $(n=7)$ or no treatment $(n=3)$. Because there were no differences between the 2 control groups, the resulting data have been combined for presentation.

$D A$ release from striatal slices. All animals were killed by decapitation. Neonatal rats were killed 7-10 d postpartum, whereas adult rats were killed 3-4 weeks after 6-HDA treatment. Brains were removed rapidly, placed on ice, and the area containing corpus striatum was dissected out bilaterally. Coronal slices ( $350 \mu \mathrm{m}$; approximately $0.4 \mathrm{ng}$ protein) were prepared using a McIlwain tissue chopper. Three slices, one each from the rostral, middle, and caudal portions of striatum, were used for the estimation of tissue DA and protein contents before superfusion. Eight additional slices were placed into a superfusion chamber $(250 \mu 1$ capacity) equipped with 2 platinum gauze electrodes. Slices were separated from one another with layers of Sephadex G-25 resin (course, $30-100 \mu \mathrm{m})$ and from the electrodes with nylon mesh (50 $\mu \mathrm{m}$ pore size). Both the small chamber volume and the Sephadex significantly improved our capacity to detect endogenous DA efflux.

Tissue was superfused at a rate of $100 \mu \mathrm{l} / \mathrm{min}$ with $37^{\circ} \mathrm{C} \mathrm{Krebs} \mathrm{bi-}$ carbonate medium containing $117 \mathrm{~mm} \mathrm{NaCl}, 4.7 \mathrm{mM} \mathrm{KCl}, 1.2 \mathrm{mM}$ $\mathrm{MgCl}_{2}, 1.25 \mathrm{~mm} \mathrm{CaCl}_{2}, 1.2 \mathrm{~mm} \mathrm{NaH} \mathrm{PO}_{4}, 25 \mathrm{~mm} \mathrm{NaHCO}, 0.015 \%$ ascorbic acid, $11.5 \mathrm{~mm}$ dextrose, and $10 \mu \mathrm{M}$ tyrosine, and was constantly bubbled with gas containing $5 \% \mathrm{CO}_{2}$ and $95 \% \mathrm{O}_{2}$. A relatively low rate of superfusion was used in order to permit equilibration between extracellular fluid and superfusing medium, and to allow the normal processes of diffusion and reuptake to take place. Five minute fractions $(500 \mu \mathrm{l})$ were collected in tubes containing $50 \mu \mathrm{l}$ of $1.1 \mathrm{~N}$ perchloric acid and $2.2 \mathrm{~mm} \mathrm{NaHSO}$ for the subsequent analysis of endogenous DA.

After superfusion for $25 \mathrm{~min}$, slices were depolarized. Field depolarization, rather than $\mathrm{KCl}$, was chosen for this purpose because of its more physiological nature, the ease with which it can be varied, and preliminary findings that $\mathrm{KCl}$ often produced a depletion of tissue DA (Keller et al., 1983a). A bipolar current pulse was used to minimize interference from ions generated by the stimulation process. Each current pulse pair consisted of a $20 \mathrm{~mA}, 2 \mathrm{msec}$ square pulse followed $0.5 \mathrm{msec}$ later by a $2 \mathrm{msec}$ pulse of the opposite sign. Unless otherwise noted, pulse pairs were delivered at $2 \mathrm{~Hz}$, a frequency that is at the low end of the physiological range (Grace and Bunney, 1984). Stimuli were generated by means of a Grass S- 88 stimulator in conjunction with a Grass SIU-5 stimulus isolation unit and a Grass CCU-1 constant current unit, and were monitored across a $1000 \Omega$ resistor placed in series with the electrode by a Tektronix D12 oscilloscope. At the end of the experiment, slices were recovered from the chamber and their protein and DA contents were measured. The amount of DA released into superfusion medium was expressed in nanograms of $\mathrm{D} \Lambda$ per milligram tissue protein per 5 min fraction. In addition, the fractional rate of DA efflux was determined by expressing the amount of DA released as a percentage of the DA present in slices prior to superfusion. Stimulation-induced overflow was calculated by subtracting fractional release during the last $5 \mathrm{~min}$ before the onset of stimulation from that observed during $5 \mathrm{~min}$ periods of stimulation.

$D A$ concentration. The DA concentration in samples of tissue and superfusate was measured by high-performance liquid chromatography with electrochemical detection. Tissue slices were homogenized in 0.1 $\mathrm{N} \mathrm{HClO}_{4}$ containing $0.2 \mathrm{mM} \mathrm{NaHSO}$ and centrifuged at $40,000 \times g$ for $15 \mathrm{~min}$. The resulting pellets were used to measure protein content. The supernatants, as well as fractions collected in the superfusion experiments, were then purified by alumina extraction and DA was measured as described previously (Keller et al., 1976; Zigmond et al., 1984). All samples yielded distinct peaks that were well above the background signal. Values were corrected for recovery using 3,4-dihydroxybenzylamine as an internal standard. Tissue values were expressed as nanograms of DA per milligram of protein.

High-affinity DA uptake. Initial rates of high-affinity DA uptake were measured in vitro using minor modifications of previous methods (Stachowiak et al., 1986). A fraction $\left(\mathrm{P}_{2}\right.$; Gray and Whittaker, 1962) containing synaptosomes, as well as mitochondria and membrane fragments, was prepared and preincubated for $5 \mathrm{~min}$ at $37^{\circ} \mathrm{C}$ with Krebs medium and $20 \mu \mathrm{M}$ pargyline. ${ }^{3} \mathrm{H}-\mathrm{DA}$-[ethyl-1- $\left.{ }^{-} \mathrm{H}(\mathrm{N})\right](44.4 \mathrm{Ci} / \mathrm{mmol})$ was then added, yielding a final DA concentration of $10 \mathrm{~nm}$, and the incubation was continued. Five minutes later, tissue was separated by filtration. The filters were washed with ice-cold incubation buffer containing $5 \mathrm{~mm}$ DA, dried, placed into scintillation vials containing $1 \mathrm{ml}$ of $0.2 \mathrm{M} \mathrm{HClO}_{4}$, and quantified by liquid-scintillation spectroscopy. Saturable high-affinity uptake (the difference between total tissue retention of tritium and tritium uptake in the presence of $0.1 \mathrm{~mm}$ unlabeled DA) was temperature-dependent and inhibited by $10 \mu \mathrm{M}$ nomifensine, but it was not affected cither by $0.5 \mu \mathrm{M}$ norepinephrine (NE) or $0.5 \mu \mathrm{M}$ 5 -HT. All samples were run in triplicate. Saturable uptake was proportional to time for a minimum of $5 \mathrm{~min}$ and to protein concentration within a range of at least 3-100 $\mu \mathrm{g} / \mathrm{sample}$. Approximately 50,000 and 5000 total cpm were obtained in samples from control and 6-HDAlesioned rats, respectively. Nonsaturable uptake yielded about 2000 $\mathrm{cpm}$ in both groups of rats. Final values were expressed as picomoles of ${ }^{3} \mathrm{H}$-DA per minute per nanogram of protein.

Tyrosine hydroxylase activity. The soluble tyrosine hydroxylase (TH) activity of crude homogenates was measured by a coupled-decarboxylase method (Waymire et al., 1971; Zigmond et al., 1984). Tissues were homogenized in $50 \mathrm{~mm}$ Tris-HCl buffer and a portion of the homogenate was used to measure DA content. The remaining homogenate was centrifuged at $40,000 \times g$ for $30 \mathrm{~min}$ and the supernatant was passed through a $5 \times 60 \mathrm{~mm}$ Scphadex G-25 column $(50-150 \mu \mathrm{m}$ particle size; Sigma). TH activity in the supernatant was measured in a $50 \mathrm{~mm}$ Trisacetate buffer (pH 5.8) containing $75 \mu \mathrm{M} \mathrm{L}-1-^{-14} \mathrm{C}$ tyrosine $(54 \mathrm{mCi} / \mathrm{mmol}$; New England Nuclear) and $3 \mathrm{mM}^{6} \mathrm{MPH}_{4}$. Samples were run in triplicate. Approximately 10,000 and 2000 total cpm were obtained from samples from control and 6-HDA-treated animals, respectively, with blank values (no tissue) of about $300 \mathrm{cpm}$. Final values were expressed as picomoles of $\mathrm{CO}_{2}$ per minute per nanogram of protein. In addition, a ratio of TH activity to DA content was used to estimate TH activity per DA terminal.

Protein. The protein content in the supernatant used for TH assay and in the synaptosomal fraction used for DA uptake was determined according to the method of Bradford (1976), whereas the protein content in tissue slices was estimated using the method of Lowry et al. (1951). Both assays were linear for up to $15 \mu \mathrm{g}$ of protein.

Statistical analyses. All values are expressed as means \pm SEM, and the number of repetitions of each experiment $(n)$ is also indicated Comparisons between 2 means were carried out by Student's $t$ test (2tailed). Comparisons between 2 patterns of DA release were made by a repeated-measures analysis of variance.

\section{Results}

\section{$D A$ efflux from adult striatum in control rats}

Striatal slices were prepared from adult control rats and superfused with Krebs bicarbonate buffer. Considerable amounts of DA were released spontaneously from these slices during the initial 5 min of superfusion; however, this efflux declined during the subsequent $20 \mathrm{~min}$ to a low, stable rate of approximately $200 \mathrm{pg} / \mathrm{min} / \mathrm{mg}$ protein (Fig. 1A). When these slices were then stimulated at $2 \mathrm{~Hz}$, efflux increased approximately 3 -fold during the first $20 \mathrm{~min}$ of continuous stimulation. DA overflow declined sharply during the next 10 min of stimulation, achieving a steady rate that was about $50-100 \%$ above the spontaneous 


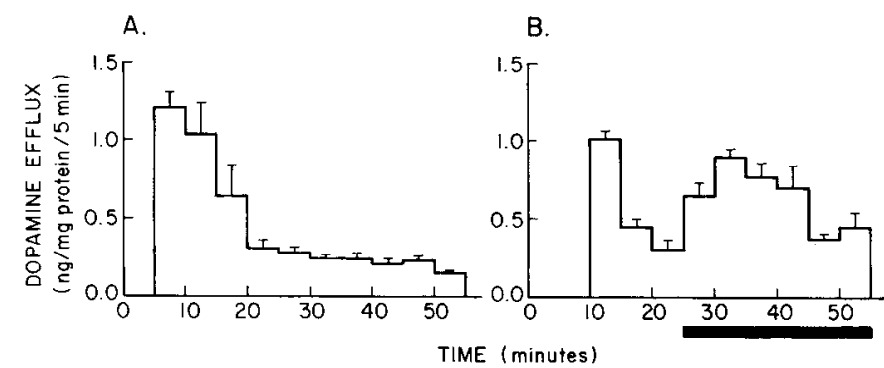

Figure 1. DA efflux from control striatal slices. DA content was measured in fractions collected every $5 \mathrm{~min}(A)$ without stimulation $(n=$ 3 ) and $(B)$ with $2 \mathrm{~Hz}$ stimulation (bar) beginning $25 \mathrm{~min}$ after the onset of superfusion $(n=3)$. Stimulation produced a significant increase in DA efflux $\left(F_{1,4}=43.9 ; p<0.01\right)$.

rate (Fig. $1 B$ ). This pattern of stimulus-induced release was eliminated by removing calcium from the perfusion medium (see below).

\section{DA efflux from neonatal striatum}

DA efflux was examined using striatal slices from 7-10-d-old rat pups and from adult animals. DA overflow from neonatal slices developed more gradually than did overflow from adult slices. However, despite the fact that the DA concentration in the striatum of neonatal rats was only $20-40 \%$ that of adult control tissue, overflow from neonatal slices reached a value 23 times higher than that of the adult control rats within 2030 min of stimulation (Fig. 2A). Moreover, when expressed as a fraction of the DA levels in freshly prepared slices, efflux from neonatal tissue was 5-6 times higher than efflux from adult tissue by the end of the stimulation period (Fig. $2 B$ ).

\section{$D A$ efflux from adult striatum in 6-HDA-treated rats}

Adult rats given 6-HDA treatments had a $60-98 \%$ loss of striatal DA. An equivalent decrease in high-affinity DA uptake was observed in synaptosome-rich homogenates of striatum (Table 1), thus suggesting that the DA content per terminal did not change substantially and can serve as an index of the extent to which DA terminals have degenerated. In contrast, in a separate group of animals the loss of TH activity was significantly less

Table 1. Striatal dopamine content and high-affinity uptake after 6-HDA lesions ${ }^{a}$

\begin{tabular}{lcl}
$\begin{array}{l}\text { Group } \\
(n)\end{array}$ & $\begin{array}{l}\text { DA content } \\
(\mathrm{ng} / \mathrm{mg} \text { protein) }\end{array}$ & $\begin{array}{l}\text { DA uptake } \\
(\mathrm{pmol} / \mathrm{mg} \\
\text { protein/min) }\end{array}$ \\
\hline Control (5) & $87.4 \pm 2.7$ & $8.12 \pm 0.53$ \\
6-HDA (5) & $9.6 \pm 2.8$ & $1.07 \pm 0.24$ \\
& $(11.0 \%)$ & $(13.2 \%)$
\end{tabular}

animals received an intraventricular injection of $6-\mathrm{HDA}(225 \mu \mathrm{g})$ or vehicle solution after intraperitoneal pretreatment with desmethylimipramine $(25 \mathrm{mg} / \mathrm{kg}$, i.p.) and pargyline $(40 \mathrm{mg} / \mathrm{kg}$, i.p.) and were killed 3 weeks later. DA contents were measured in homogenates, and accumulations of $10 \mathrm{nM}^{3} \mathrm{H}-\mathrm{DA}$ were measured in crude synaptosomal fractions prepared from the same tissue sample. Numbers represent means \pm SEM or percentages of sham-lesioned controls.

${ }^{b}$ IIigh-affinity DA uptake was calculated by subtracting uptake obtained in the presence of $0.1 \mathrm{~mm}$ unlabeled DA from the total tissue retention of tritium. In a single experiment, DA uptake was measured in the presence of $10 \mu \mathrm{M}$ nomifensine added $5 \mathrm{~min}$ prior to ${ }^{3} \mathrm{H}-\mathrm{D} \Lambda$ and was found to be $0.80 \mathrm{pmol} / \mathrm{mg}$ protein $/ \mathrm{min}$.

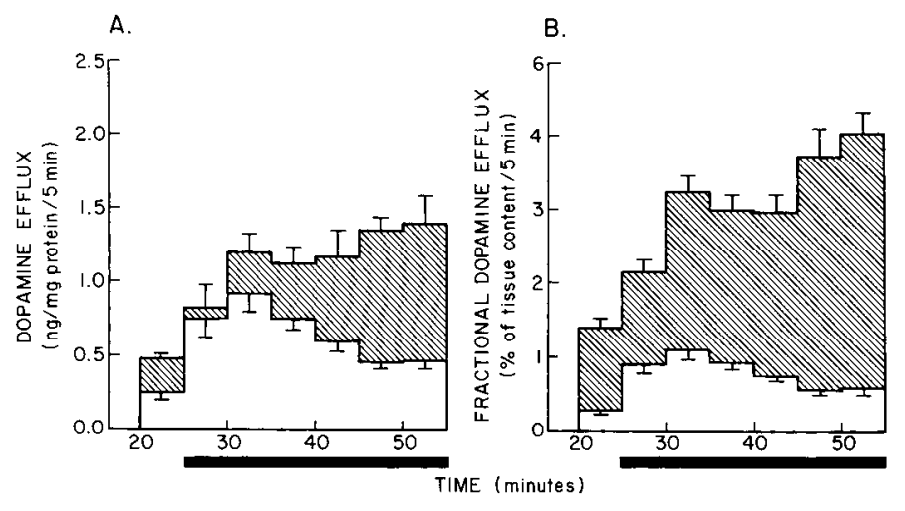

Figure 2. DA efflux from slices prepared from neonatal rats. DA efflux from striatal slices of 7-10-d-old rat pups $(n=6$; shaded area) was compared with efflux from adult slices $(n=10$; open area). Slices were superfused for $25 \mathrm{~min}$ under basal conditions and then subjected to 2 Hz stimulation for $30 \mathrm{~min}$ (bar). DA efflux is expressed $(A)$ per milligram of protein and $(B)$ as fractional efflux, i.e., the percentage of the DA content of adjacent slices prior to incubation. The DA content of slices from adult and neonatal rats was $82.3 \pm 3.9$ and $35.2 \pm 4.5 \mathrm{ng} / \mathrm{mg}$ protein, respectively. Stimulated efflux was significantly greater than from neonatal slices, whether expressed per milligrams of protein $\left(F_{1,10}=\right.$ $22.99 ; p<0.01)$ or as fractional efflux $\left(F_{1.10}=197.96 ; p<0.01\right)$.

than the loss of DA, leading to an increase in the ratio of $\mathrm{TH}$ activity to DA content (Table 2; see also Zigmond et al., 1984).

When DA efflux was examined 3-4 weeks after the lesion, it was found that striatal slices from the brain-damaged rats responded to the onset of electrical stimulation by increasing the efflux. Considerably more DA efflux was observed than might have been predicted by the extent of DA loss from tissue, resulting in a significant increase in fractional DA efflux. The pattern of increase was different from that observed with control slices from adult rats, resembling, instead, that observed with slices from neonatal animals. Thus, during depolarization, DA efflux rose less rapidly at first than did efflux from adult control tissue, and exhibited little or no decline (Fig. 3). Greater increases in fractional DA cfflux were observed in slices with larger lesions (Fig. 4).

\section{$D A$ efflux as a function of stimulus frequency}

Because DA neurons normally tend to fire at a relatively low rate, with brief periods of increased activity (Grace and Bunney, 1979; Chiodo et al., 1980; Steinfels et al., 1983), we examined the response of striatal slices to sustained low-frequency stim-

Table 2. Dopamine and tyrosine hydroxylase activity in striatum after 6-HDA administration

\begin{tabular}{|c|c|c|c|}
\hline $\begin{array}{l}\text { Group } \\
(n)\end{array}$ & $\begin{array}{l}\text { DA content } \\
\text { (ng/mg protein) }\end{array}$ & $\begin{array}{l}\text { TH activity } \\
\text { (pmol/ } \\
\mathrm{mg} \text { protein } / \mathrm{min} \text { ) }\end{array}$ & $\begin{array}{l}\text { TH/DA } \\
\left(\times 10^{3}\right)\end{array}$ \\
\hline Control (6) & $76.0 \pm 6.6$ & $0.94 \pm 0.08$ & $11.9 \pm 0.5$ \\
\hline 6-HDA (6) & $\begin{array}{l}4.1 \pm 0.8 \\
(5.4 \%)\end{array}$ & $\begin{array}{l}0.11 \pm 0.01 \\
(11.7 \%)\end{array}$ & $\begin{array}{l}28.2 \pm 1.9 \\
(234 \%)\end{array}$ \\
\hline
\end{tabular}

Rats were killed 3 weeks after surgery. TH activity and DA content were measured in the same homogenate (see Materials and Methods). Values represent means \pm SEM or percentages of sham-lesioned controls. TH activity and DA content were significantly lower in 6-HDA-treated animals than in controls $(p<0.001)$, whereas the ratio of these variables was significantly higher $(p<0.001)$. 


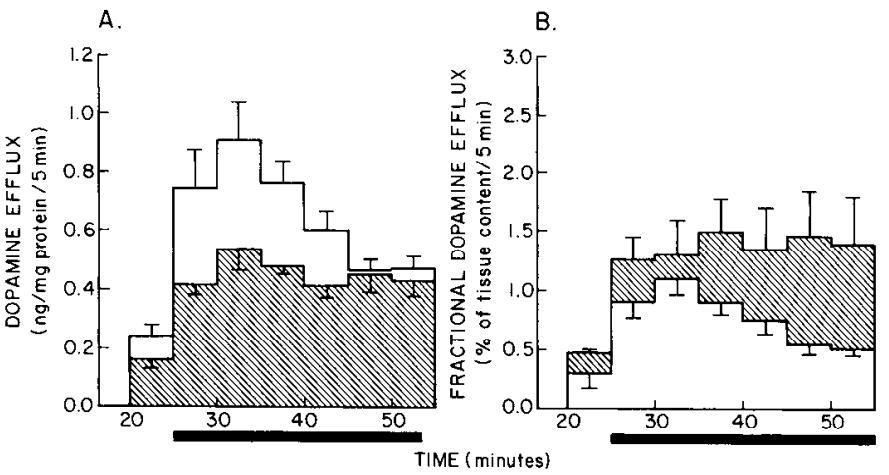

Figure 3. DA efflux from slices prepared from 6-HDA-treated animals. DA efflux from striatal slices of 6-HDA-treated rats ( $n=3$; shaded area) was compared with efflux from vehicle-treated control animals $(n=10$; open area). Striatal slices were superfused for $25 \mathrm{~min}$ under basal conditions and then subjected to $2 \mathrm{~Hz}$ stimulation for $30 \mathrm{~min}$ (bar). DA efflux is expressed $(A)$ per milligram of protein and $(B)$ as fractional DA release. Slices from 6-HDA-treated rats showed DA depletions of approximately $58 \%$ (mean \pm SEM: vehicle, $82.3 \pm 4.2 \mathrm{ng} / \mathrm{mg}$ protein; 6 -HDA, $34.5 \pm 2.4 \mathrm{ng} / \mathrm{mg}$ protein). Stimulated efflux was significantly greater than that from intact slices, as expressed per milligram of protein $\left(F_{16}=22.42 ; p<0.01\right)$ and from 6-HDA-treated slices when expressed as fractional efflux $\left(F_{1,6}=13.88 ; p<0.01\right)$.

ulation and to brief high-frequency stimulation. Slices prepared from adult control animals were exposed to $70 \mathrm{~min}$ of stimulation at $2 \mathrm{~Hz}$, interrupted at $35 \mathrm{~min}$ by a $3 \mathrm{~min}$ period of stimulation at $20 \mathrm{~Hz}$. Using this paradigm, we observed that once the initial 10-15 min period of rapid efflux was complete, slices maintained a relatively stable ratc of calcium-dependent efflux in response to $2 \mathrm{~Hz}$ stimulation (Fig. 5). During the $5 \mathrm{~min}$ period initiated by the onset of $20 \mathrm{~Hz}$ stimulation, efflux increased 5-fold, while overflow increased almost 10-fold (Figs. $5 A ; 6)$.

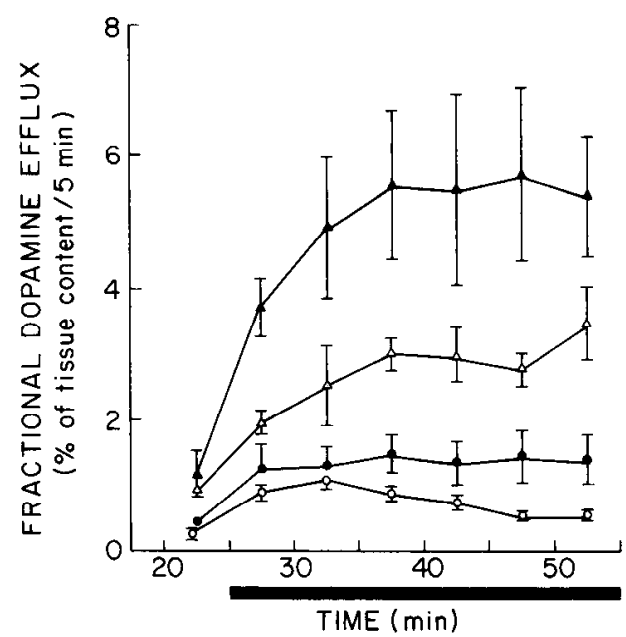

Figure 4. Effect of 6-HDA-induced lesions on DA release from striatal slices. Rats received 6-HDA or vehicle and were killed 4 weeks later. Striatal slices were superfused for $25 \mathrm{~min}$ under basal conditions and then subjected to $2 \mathrm{~Hz}$ stimulation for $30 \mathrm{~min}$ (bar). Data are grouped by level of lesion-induced DA depletion, as determined from adjacent, nonincubated slices, and are expressed as fractional DA efflux as a function of time. In each group of 6-HDA-lesioned slices, fractional DA efflux was significantly greater than efflux from intact slices. Open circles, vehicle-injected controls $(n=10)$; closed circles, 50-80\% DA depletion $(n=3)\left(F_{1.6}=13.88 ; p<0.01\right)$; open triangles, 80-96\% DA depletion $(n=6)\left(F_{1,10}=85.91 ; p<0.01\right)$; closed triangles, 96\% DA depletion $(n=7)\left(F_{1,10}=28.52 ; p<0.01\right)$.
A.

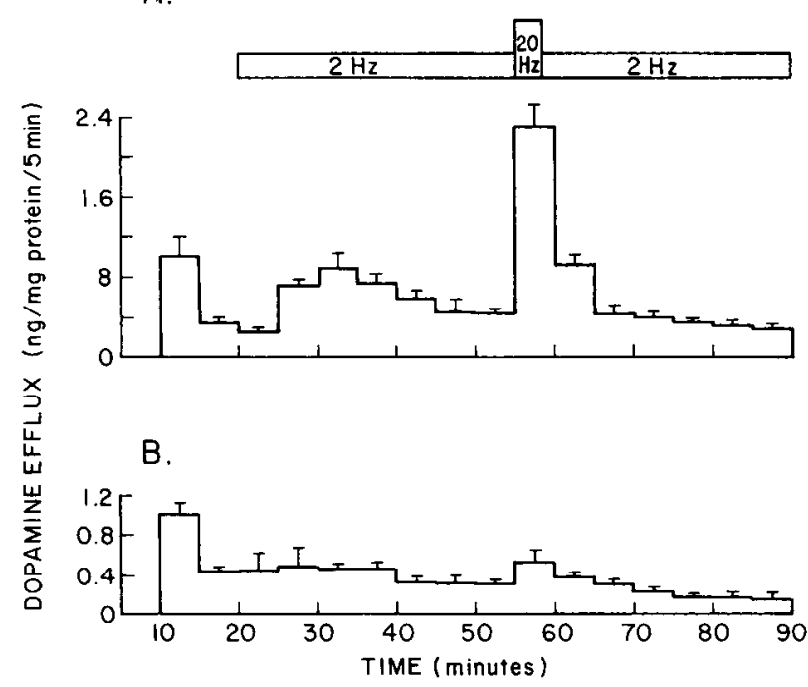

Figure 5. DA efflux from control slices during low- and high-frequency stimulation. Striatal slices were superfused for $20 \mathrm{~min}$ without stimulation, then subjected to $2 \mathrm{~Hz}$ stimulation, interrupted after $35 \mathrm{~min}$ by a $3 \mathrm{~min}$ period of $20 \mathrm{~Hz}$ (bars). The superfusion medium consisted either of $(A)$ normal Krebs buffer containing $1.25 \mathrm{mM} \mathrm{CaCl}_{2}(n=9)$ or (B) calcium-free buffer containing $5 \mathrm{~mm}$ EGTA $(n=3)$. Stimulation in the presence of calcium produced a significant increase in DA efflux $(p<0.01$ ), with efflux at $20 \mathrm{~Hz}$ being significantly greater than at $2 \mathrm{~Hz}$ $(p<0.01)$. There was no significant effect of stimulation in the absence of calcium.

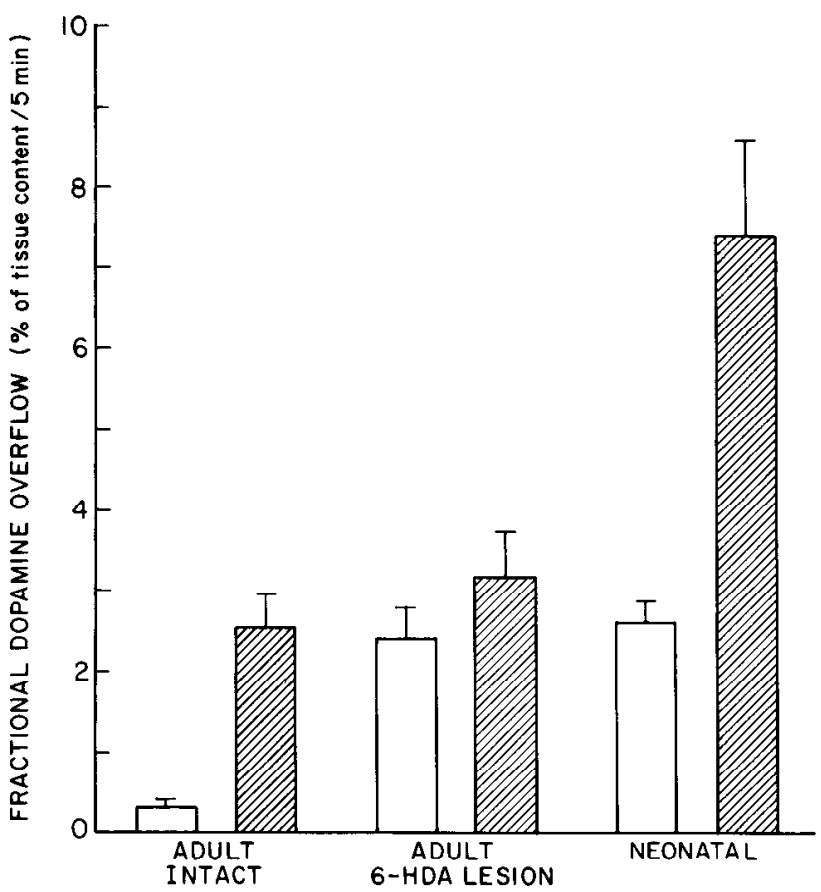

Figure 6. DA overflow from striatal slices during low- and high-frequency stimulation. Slices from adult intact (vehicle-treated) rats $(n=$ 9), 6-HDA-treated rats (4 weeks postlesion; $n=10$ ), and neonatal (710-d-old) rat pups $(n=6)$ were treated as described in the legend to Figure 5. DA overflow was calculated by subtracting the spontaneous efflux measured in the fraction collected 20-25 min after the beginning of superfusion from efflux collected during stimulation. DA overflow during $2 \mathrm{~Hz}$ stimulation delivered between 50 and $55 \mathrm{~min}$ (empty bars) was compared to the overflow produced by $3 \mathrm{~min}$ of $20 \mathrm{~Hz}$ stimulation, followed by $2 \mathrm{~min}$ of $2 \mathrm{~Hz}$ stimulation, delivered between 55 and 60 min (hatched bars). DA content in striatum of adjacent, noninjected control, $82.3 \pm 3.9 \mathrm{ng} / \mathrm{mg}$ protein; of 6 -HDA-lesioned, $5.1 \pm 0.7 \mathrm{ng} /$ $\mathrm{mg}$ protein; and of neonates, $35.2 \pm 4.5 \mathrm{ng} / \mathrm{mg}$ protein. 

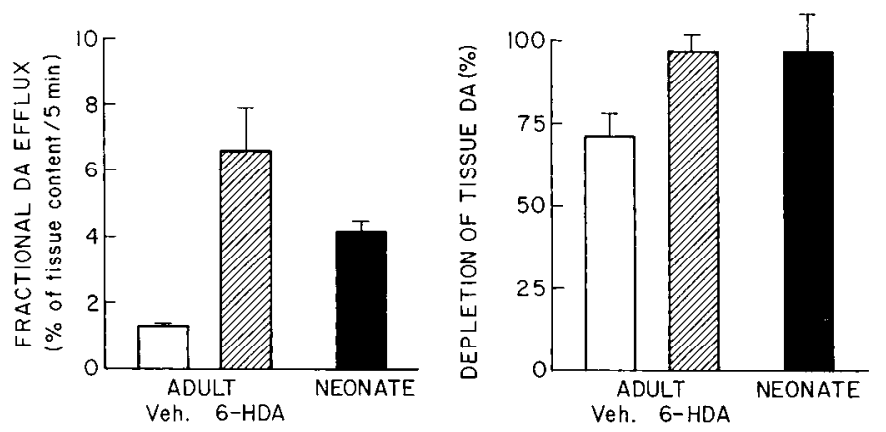

Figure 7. Effect of stimulation on DA efflux and tissue DA content. At the end of the experiment described in the legend to Figure 6 , the amount of DA recovered in the superfusate and the concentration of DA remaining in the tissue slices were determined. Shown are values for adult animals treated with 6-HDA or vehicle ( $V e h$.) 4 weeks prior to the experiment, and for neonatal (7-10-d-old) rat pups. Fractional DA efflux from slices prepared from adult lesioned animals and neonatal pups was significantly greater than that from adult control animals $(p<$ $0.01)$. DA depletion was significant only in slices from intact control animals $(p<0.01)$.

Fractional DA efflux from slices prepared from neonatal rats and stimulated at $2 \mathrm{~Hz}$ was higher than that observed from adult control slices, as has been shown previously. Efflux from neonatal slices increased significantly when slices were stimulated at $20 \mathrm{~Hz}$, although the ratio of overflow at $20 \mathrm{~Hz}$ to that at $2 \mathrm{~Hz}$ was only 2.8 , less than in adult slices (8.5). Slices from 6-HDA-treated animals, on the other hand, showed a high fractional DA efflux in response to $2 \mathrm{~Hz}$ stimulation but no further increase in response to $20 \mathrm{~Hz}$ (Fig. 6).

After $60 \mathrm{~min}$ of stimulation, the total amount of DA lost to the superfusion fluid was calculated and the concentration of DA remaining in the tissue was determined. Slices from 6-HDAtreated rats and neonatal rats released an amount of $D \Lambda$ equivalent to 80 and $50 \%$ of their total DA content, respectively, but no loss of tissue DA could be detected. By contrast, slices from control animals released the equivalent of only $16 \%$ of their DA content to the superfusion fluid, yet showed a $28 \%$ DA depletion (Fig. 7).

\section{Increased release versus decreased reuptake}

The increase in fractional DA efflux from striatum of 6-HDAtreated rats could be due to an increase in DA release by residual terminals, a decrease in DA reuptake from the synaptic cleft, or both. To determine the relative contributions of alterations in release and uptake, striatal slices were stimulated at $2 \mathrm{~Hz}$ for $15 \mathrm{~min}$ in the presence of normal buffer, and stimulation was continued in the presence of nomifensine $(10 \mu \mathrm{M})$, a treatment that inhibited DA uptake by $90 \%$ (Table 1). With slices from adult control rats, nomifensine produced an immediate increase in DA efflux, whereas there were much smaller responses with slices from the 6-HDA-treated rats (Fig. 8A). When these effects were expressed in terms of fractional efflux, DA efflux from control slices in the presence of nomifensine still was only about $50 \%$ of that observed from the other slices (Fig. $8 B$ ).

\section{Discussion}

Intraventricular injections of 6-HDA resulted in parallel decreases in the concentration of DA and the rate of high-affinity DA uptake in striatum, as has been noted previously (Uretsky and Iversen, 1970; Zigmond et al., 1984). 6-HDA treatment
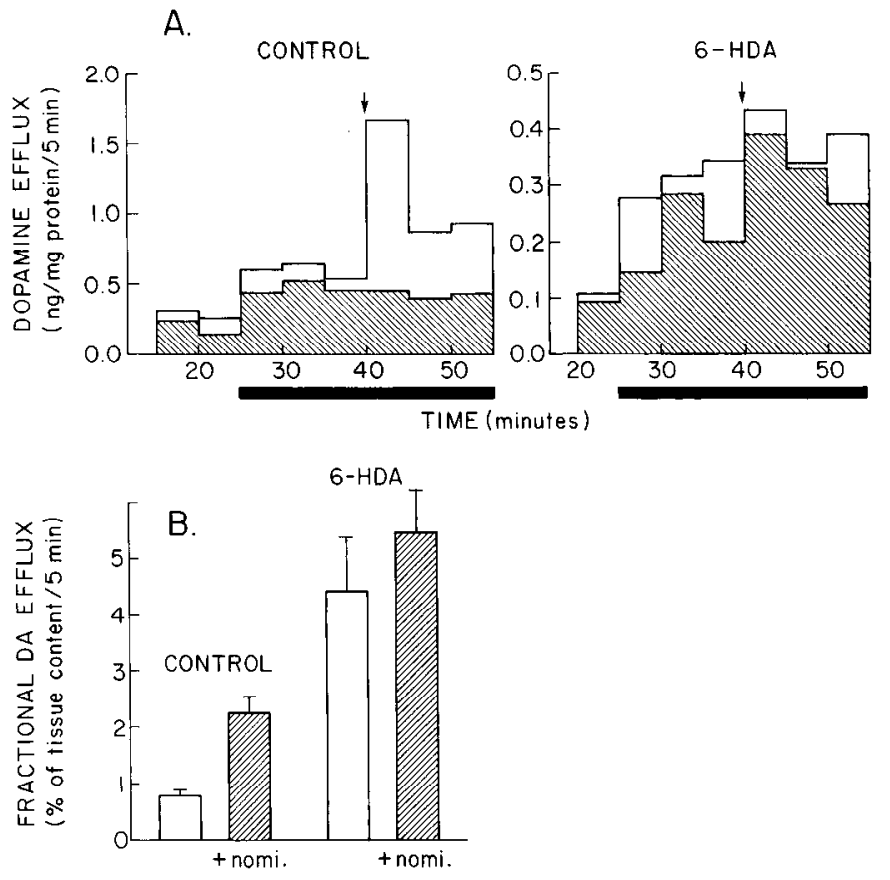

Figure 8. Effect of nomifensine on DA efflux. Striatal slices from vehicle-injected control and 6-HDA-lesioned rats were superfused for 25 min under basal conditions and then exposed to $30 \mathrm{~min}$ of $2 \mathrm{~Hz}$ stimulation (bar). Nomifensine $(10 \mu \mathrm{M})$ was introduced into the buffer after the first 15 min of stimulation. $A$, DA efflux in a representative experiment as a function of time (standard medium, hatched area; nomifensine, open area). Arrow indicates introduction of nomifensine into the superfusion medium. $B$, Fractional rates of DA efflux from striatal slices during the $5 \mathrm{~min}$ immediately before (open bars) and after (hatched bars) addition of nomifensine (nomi.) from control $(n=5)$ and 6-HDAlesioned $(n=7)$ rats. Nomifensinc significantly incrcascd cfflux from slices from control animals $(p<0.01)$, but had no significant effect on efflux from slices from 6-HDA-treated rats $(p>0.10)$.

also decreased the rate of DA overflow from striatal slices, but this effect was considerably smaller than that of the loss of DA content, resulting in a significant increase in the fractional rate of DA overflow. The extent of this increase was related to lesion size. For example, a $60-80 \%$ depletion of striatal DA was associated with a 3.5 -fold increase in fractional DA overflow, whereas $96 \%$ DA depletion was accompanied by a 7 -fold increase.

The reduction in high-affinity DA uptake sites after 6-HDA treatment should contribute to the increase in fractional DA efflux. To assess this contribution, we measured DA efflux in control tissue after inhibiting high-affinity DA uptake with nomifensine and observed a 2-fold increase. However, fractional DA efflux in striatal tissue from brain-damaged rats was increased 3- to 7-fold. Thus, assuming that DA is normally inactivated by a nomifensine-sensitive process, it appears that there was an increase in the release of DA from residual terminals as well. These observations are reminiscent of our previous findings that, after 6-HDA-induced lesions in adult rats, there is in striatal tissue a disproportionately large concentration of dihydroxyphenylacetic acid (DOPAC), the deaminated metabolite of DA, and that the ratio of DOPAC to DA content increases exponentially as a function of DA depletion (Zigmond et al., 1984).

These observations suggest that partial destruction of DA terminals is accompanied by a significant increase in the capacity 
of the residual terminals to deliver DA to distant sites. This increase may account for previous findings that lesions of the nigrostriatal bundle produce relatively few deficits in basal striatal function, and no gross behavioral dysfunctions, unless the loss of striatal DA is severe (Zigmond and Stricker, 1973; MacKenzie et al., 1985; Orr et al., 1986). Moreover, the present observation that striatal slices from 6-HDA-treated rats are unable to increase DA release in response to a large increase in stimulus frequency may be related to previous findings that rats with DA-depleting brain lesions, which behave normally in a neutral laboratory setting, show behavioral impairments when exposed to stressful stimuli, such as tail shock, that are known to release DA (Keller et al., 1983b; Snyder et al., 1985). Thus, these studies in isolated tissue may illuminate the behavioral syndrome that results from DA-depleting brain lesions.

The gradual development of the dopaminergic projection to striatum provides another condition under which the functional impact of DA hypoinnervation may be examined. Although the first neurites from substantia nigra reach the striatum early in development, innervation is not complete until about day 40 postpartum (Kirskey and Slotkin, 1979). In the present studies, striatal DA levels at days $7-10$ were 20 to $40 \%$ of adult levels, but the rate of stimulated $\mathrm{D} \Lambda$ efflux was comparable to that seen in the adult, indicating a significant increase in fractional DA efflux. This enhanced capacity for DA release may account for previous findings that DA control over striatal neurons (Coyle and Campochiaro, 1976) and behavior (Lal and Sourkes, 1973; Baez et al., 1976) matures well before the adult density of dopaminergic innervation is attained.

The increases in DA overflow seen after lesions were induced in adult animals by 6-HDA, and in neonatal rats, apparently were accompanied by an increase in DA synthesis. This is indicated in each case by the failure of tissue DA levels to decline during stimulation and by the relative increase in TH activity (Porcher and Heller, 1972; Coyle and Campochiaro, 1976; Zigmond et al., 1984; and the present study). We conclude that the increased synthesis and release and the decreased reuptake of DA all serve to compensate for hypoinnervation after injury or during development.

\section{References}

Agid, Y., F. Javoy, and J. Glowinski (1973) Hyperactivity of remaining dopaminergic neurons after partial destruction of the nigro-striatal dopaminergic system in the rat. Nature 245: 150-151.

Agid, Y., P. Guyenet, J. Glowinski, J. Beaujouan, and F. Javoy (1975) Inhibitory influence of the nigrostriatal dopaminc systcm on the striatal cholinergic neurons in the rat. Brain Res. 86: 488-492.

Baez, L. A., N. K. Eskridge, and R. Schein (1976) Postnatal development of dopaminergic and cholinergic catalepsy in the rat. Eur. J. Pharmacol. 36: 155-162.

Bradford,, M. M. (1976) A rapid and sensitive method for the quantitation of microgram quantities of protein utilizing the principle of protein-dye binding. Anal. Biochem. 72: 248-254.

Breese, G. R., and T. D. Traylor (1970) Effect of 6-hydroxydopamine on brain norepinephrine and dopamine: Evidence for selective degeneration of catecholamine neurons. J. Pharmacol. Exp. Ther. 174: $413-420$.

Chiodo, L. A., A. R. Caggiula, S. M. Antelman, and C. G. Lineberry (1980) Sensory stimuli alter the discharge rate of dopamine (DA) neurons: Evidence for two functional types of DA cells in the substantia nigra. Brain Res. 189: 544-549.

Coyle, J. T., and P. Campochiaro (1976) Ontogenesis of dopaminergic-cholinergic interactions in the rat striatum: A neurochemical study. J. Neurochem. 27: 673-678.

Creese, J., and S. H. Snyder (1979) Nigrostriatal lesions enhance stria- tal ${ }^{3} \mathrm{H}$-apomorphine and ${ }^{3} \mathrm{H}$-spiroperidol binding. Eur. J. Pharmacol. 56: $277-281$.

Cubeddu, L. X., and J. S. Hoffman (1983) Frequency-dependent release of acetylcholine and dopamine from rabbit striatum: Its modulation by dopaminergic receptors. J. Neurochem. 41: 94-101.

Farnebo, L. O., and B. Hamberger (1971) Drug-induced changes in the release of ${ }^{3} \mathrm{H}$-monoamines from field stimulated rat brain slices. Acta Physiol. Scand. (Suppl.) 371: 35-44.

Grace, A. A., and B. S. Bunney (1979) Paradoxical GABA excitation of nigral dopaminergic cells: Indirect mediation through reticulata neurons. Eur. J. Pharmacol. 59: 211-218.

Grace, A. A., and B. S. Bunney (1984) The control of firing pattern in nigral dopamine neurons: Single spike firing. J. Neurosci. 4:28662876.

Gray, F. G., and V.P. Whittaker (1962) The isolation of nerve endings from brain: An electron microscopic study of cell fragments derived by homogenization and centrifugation. J. Anat. 96: 79-88.

Hefti, F., E. Melamed, and R. J. Wurtman (1980) Partial lesions of dopaminergic nigrostriatal system in rat brain: Biochemical characterization. Brain Res. 195: 123-128.

Kapatos, G., and M. J. Zigmond (1979) Effect of haloperiodol on DA synthesis and tyrosine hydroxylase in striatal synaptosomes. J. Pharmacol. Exp. Ther. 208: 468-475.

Keller, H., G. Bartholini, and A. Pletscher (1973) Spontaneous and drug-induced changes of cerebral dopamine turnover during postnatal development of rats. Brain Res. 64: 371-378.

Keller, R., A. Oke, I. Mefford, and R. Adams (1976) Liquid chromatographic analysis of catecholamines: Routine assay for regional brain mapping. Life Sci. 19: 995-1004.

Keller, R. W., Jr., K. L. Frayer, M. R. Petrus, and M. J. Zigmond (1983a) In vitro release of endogenous dopamine: Effects of depolarization. Soc. Neurosci. Abstr. 9: 990.

Keller, R. W., Jr., E. M. Stricker, and M. J. Zigmond (1983b) Environmental stimuli but not homeostatic challenges produce apparent increases in dopaminergic activity in the striatum: An analysis by in vivo voltammetry. Brain Res. 279: 159-170.

Kirskey, D. F., and T. A. Slotkin (1979) Concomitant development of $(3 \mathrm{H})$-dopamine and $(3 \mathrm{H})$-5-hydroxytryptamine uptake systems in rat brain regions. Br. J. Pharmacol. 67: 387-391.

Lal, S., and T. L. Sourkes (1973) Ontogeny of stereotyped behavior induced by apomorphine and amphetamine in the rat. Arch. Int. Pharmacodyn. 202: 171-182.

Lowry, O. H., N. J. Rosebrough, A. L. Farr, and R. J. Randall (1951) Protein measurement with folin phenol reagent. J. Biol. Chem. 193: 265-275.

MacKenzie, R. G., M. K. Stachowiak, E. M. Stricker, and M. J. Zigmond (1985) Restoration of dopaminergic inhibition of cholinergic function after partial damage to the nigro-striatal bundle. Soc. Neurosci. Abstr. 11:891.

Marshall, J. F., J. S. Richardson, and P. Teitelbaum (1974) Nigrostriatal bundle damage and the lateral hypothalamic syndrome. J. Comp. Physiol. Psychol. 87: 808-830.

Noble, E. P., R. J. Wurtman, and J. Axelrod (1967) A simple and rapid method for injecting $3 \mathrm{H}$-norepinephrine into lateral ventricle of the rat brain. Life Sci. 6: 281-291.

Orr, W. B., T. W. Gardiner, E. M. Stricker, M. J. Zigmond, and T. W. Berger (1986) Short-term effects of dopamine-depleting brain lesions on spontaneous activity of Type II striatal neurons: Relation to local dopamine concentration and behavior. Brain Res. 376: 20-28.

Pardo, J. V., I. Creese, D. R. Burt, and S. H. Snyder (1977) Ontogenesis of dopamine receptor binding in the corpus striatum of the rat. Brain Res. 125: 376-382.

Porcher, W., and A. Heller (1972) Regional development of catecholamine biosynthesis in rat brain. J. Neurochem. 19: 1917-1930.

Raiteri, M., M. Marchi, and G. Maura (1984) Release of catecholamines, serotonin, and acetylcholine from isolated brain tissue. In Handbook of Neurochemistry, vol. 6, 2nd Ed., A. Lajtha, ed., pp. 431462, Plenum, New York.

Rommelspacher, H., and M. Kuhar (1975) Effects of dopaminergic drugs and acute medial forebrain bundle lesions on striatal acetylcholine levels. Life Sci. 16: 65-70.

Schultz, W., and U. Ungerstedt (1978) Short-term increase and longterm reversion of striatal cell activity after degeneration of the nigrostriatal dopamine system. Exp. Brain Res. 33: 159-171.

Snyder, A. M., E. M. Stricker, and M. J. Zigmond (1985) Stress- 
induced neurological impairments in an animal model of Parkinsonism. Ann. Neurol.18: 544-551.

Stachowiak, M. K., J. P. Bruno, E. M. Stricker, and M. J. Zigmond (1984) Increased striatal dopamine release accompanies hypoinnervation of striatum during development or after 6-hydroxydopamine. Soc. Neurosci. Abstr. 10: 880 .

Stachowiak, M. K., E. M. Stricker, J. H. Jacoby, and M. J. Zigmond (1986) Increased tryptophan hydroxylase activity in serotonergic nerve terminals spared by 5,7-dihydroxytryptamine. Biochem. Pharmacol. 35: 1241-1248.

Starke, K., W. Reinmann, A. Aumstein, and G. Hertting (1978) Effect of dopamine receptor agonists and antagonists on release of dopamine in the rabbit caudate nucleus in vitro. Naunyn Schmiedebergs Arch. Pharmacol. 305: 27-36.

Steinfels, G. F., J. Heym, R. E. Strecker, and B. L. Jacobs (1983) Behavioral correlates of dopaminergic unit activity in freely moving cats. Brain Res. 258: 217-228.

Ungerstedt, U. (1971) Adipsia and aphagia after 6-hydroxydopamine induced degeneration of the nigrostriatal dopamine system. Acta Physiol. Scand. (Suppl.) 367: 95-122.

Uretsky, N. J., and L. L. Iversen (1970) Effects of 6-hydroxydopaminc on catecholamine containing neurons in the rat brain. J. Neurochem. 17: 269-278.

Waymire J. C., R. Bjur, and N. Weiner (1971) Assay of tyrosine hydroxylase by coupled decarboxylation of dopa formed by $1-{ }^{14} \mathrm{C}-\mathrm{L}-$ tyrosine. Anal. Biochem. 43: 588-600.

Zigmond, M. J., and E. M. Stricker (1973) Recovery of feeding and drinking by rats after intraventricular 6-hydroxydopamine or lateral hypothalamic lesions. Science 182: 717-720.

Zigmond, M. J., and E. M. Stricker (1980) Supersensitivity after intraventricular 6-hydroxydopamine: Relation to dopamine depletion. Experientia 36: 436-438.

Zigmond, M. J., A. L. Acheson, M. K. Stachowiak, and E. M. Stricker (1984) Neurochemical compensation after nigrostriatal bundle injury in an animal model of preclinical parkinsonism. Arch. Neurol. 41 : 856-861. 